\title{
GAJAH MADA SANG MAHA PATIH PEMERSATU NUSANTARA DI BAWAH MAJAPAHIT TAHUN 1336 M - 1359 M
}

\author{
Agus Susilo $^{1}$, Andriana Sofiarini ${ }^{2}$ \\ STKIP PGRI Lubuklinggau ${ }^{1,2}$ \\ agussusilo594@yahoo.co.id
}

\begin{abstract}
ABSTRAK
Tujuan penelitian ini untuk mengetahui sejarah Gajah Mada Sang Maha Patih Pemersatu Nusantara. Penelitian ini menggunakan metode Sejarah dengan mengumpulkan sumber primer maupun sekunder. Hasil penelitian Pada masa Hayam Wuruk, Kerajaan Majapahit mengalami puncak kejayaan berkat peran Patih Amngkubhumi Gajah Mada, yang ditandai dengan sumpah Amukti Palapa untuk mewujudkan penyatuan wilayah Nusantara. Simpulan Kerajaan Majapahit merupakan salah satu Kerajaan terbesar di Nusantara. Pada masa kejayaan kerajaan Majapahit dimasa kepemimpinan Raja Hayam Wuruk, membentuk Majapahit menjadi makmur dan mengalami masa yang sangat jaya. Mahapatih Gajah Mada yang mengucapkan Sumpahnya yang terkenal dengan nama sumpah Amukti Palapa. Mengandalkan strategi militer dan politik yang baik, Mahapatih Gajah Mada mampu mengaplikasikan sumpah Amukti Palapanya, sehingga menjadikannya Patih yang paling disegani di Kerajaan Majapahit maupun di wilayah-wilayah lain.
\end{abstract}

Kata Kunci : Gajah Mada, Nusantara, Majapahit

\section{ABSTRACT}

The purpose of this study is to find out the history of the Elephant Maiden of the United States National Guard. This research uses the History method by collecting primary and secondary sources. Research results During the Wuruk Chicken, the Majapahit Kingdom experienced a peak of success thanks to the role of Patih Amngkubhumi Elephant Mada, which was marked by the oath of Amukti Palapa to establish a unification of the Archipelago. The Majapahit Kingdom knot is one of the largest Kingdoms in the archipelago. At the time of the success of the Majapahit kingdom under the leadership of King Hayam Wuruk, the Majapahit became prosperous and had a very successful period. Obviously the Mada elephant reciting his Oath which is known by the name of Amukti Palapa. Relying on good military and political strategies, Mahapatih Elephant Mada was able to apply his Palatine oath, making him the most respected duke in the Majapahit Kingdom and in other territories.

Keywords: Gajah Mada, Archipelago, Majapahit 


\section{PENDAHULUAN}

Kepulauan Indonesia berada pada posisi yang strategis, merupakan penghubung benua Asia dan benua Australia. Bangsa Indonesia dikenal dengan bangsa yang pandai mengarungi lautan samudra dan kotakota di Nusantara tumbuh menjadi pusat-pusat perdagangan di beberapa daerah pesisir Pulau Sumatera dan Jawa. Kepulauan Indonesia merupakan bagian dari satu kesatuan daerah lalu lintas barang. Pada permulaan perhitungan tarikh Masehi, Indonesia menjadi kiblat perdagangan dunia, khususnya pedagang dari India. Peristiwa ini kemudian disusul oleh kejadian-kejadian yang serupa menimbulkan hubungan kebudayaan yang disusul oleh hubungan politik antar bangsa-bangsa luar di Indonesia sehingga memunculkan kebudayaan Hindu dan Buddha (Suwardono, 2013).

Dalam sejarah kerajaan di Jawa yang bermula dari Kerajaan Mataram Kuno sampai Kerajaan Mataram Islam tidak dapat dilepaskan dengan politik. Melalui politik, suatu kerajaan dapat berdiri mencapai kejayaan kemudian mengalami kehancuran sebelum munculnya kerajaan baru. Berkaitan dengan politik yang cenderung digunakan raja-raja atau tokoh-tokoh Kerajaan di Jawa untuk mencapai kekuasaan yang mana politik digunakan untuk mendapatkan atau merebut kekuasaan dari pihak lain (Achmad, Sri Wintala, 2016).

Sebagai Kerajaan Maritim nasional, Jawa didukung oleh Kerajaan-Kerajaan lain, yang kapasitasnya sejajar dan tidak berhadapan maupun diperintah mutlak oleh Jawa. Sistem administasi wilayah Majapahit terutama penerapan sistem persekutuan daerah atau monco-limadesa bukan merupakan daerah hukum, tidak mempunyai pemerintahan sendiri, tetapi seorang warga dari monco-pat atau monco-lima-desa ditunjuk sebagai kepalanya. Karena bukan daerah hukum, tidak ada nama untuk wilayah kesatuan antara kerajaan Jawa dan Nusantara (Nugroho, Irawan Djoko, 2011).

Sejarah Kerajaan Majapahit dalam sejarah bangsa Indonesia tidak bisa melepaskan dari Kerajaan Singasari. Dari sini dapat disebutkan bahwa secara garis keturunan, pendiri Kerajaan Majapahit merupakan pewaris kekuasaan Kerajaan Singasari yang sebelumnya runtuh. Pembukaan hutan Tarik untuk mendirikan Kerajaan Majapahit oleh Raden Wijaya merupakan pendiri dari Kerajaan Majapahit. Raden Wijaya berusaha menarik simpati penduduk sekitarnya, sehingga ia kemudian banyak disukai oleh para penduduk sekitar. Banyak sekali orang-orang yang mempunyai keinginan untuk bertempat tinggal di Majapahit saat itu. Raden Wijaya sebenarnya akan menjadikan Majapahit sebagai kerajaan yang menghancurkan Jayakatwang (Pinuluh, Esa Damar, 2010:).

Kembalinya armada Tartar ke negerinya, dengan sendirinya kekuasaan Jawa menjadi kosong. Kesempatan inilah yang ditunggu oleh Wilaya untuk menobatkan dirinya menjadi Raja Majapahit. Penobatan itu terjadi 10 November 1293 M (Djafar, 2009). Raden Wijaya menjadi Raja 
Majapahit dengan gelar Sri Kertarajasa Jayawarddhana. Pengikutpengikut Kerajaan Majapahit diberikan kesempatan untuk menikmati hasil perjuangannya (Suwardono, 2013).

Pada masa itu, tepatnya pada abad ke-14, lahirlah seorang tokoh bangsa dari kalangan rakyat jelata, dari kasta yang tidak diperhitungkan. Berbekal falsafah persatuan Nusantara yang tertuang di dalam serat Pararaton, Sumpah Amukti Palapa, yang diucapkan di Paseban Agung Majapahit pada tahun 1334, Gajah Mada seorang tokoh politik pada zaman itu telah memberikan inspirasi yang sangat besar bagi pembentukan negara kesatuan Republik Indonesia. Keberhasilan mempersatukan bangsa yang heterogen ini telah memperkaya budaya bangsa menjadi bangsa yang besar dan berwibawa di mata negara tetangga. Falsafah persatuan dan kesatuan yang dicanangkannya itu terbukti telah membawa bangsa ini ke zaman keemasan (Masmada, Renny, 2003).

Mahapatih Gajah merupakan seorang tokoh nasional pada masa kejayaan Kerajaan Majapahit. Di dalam Kakawin Gajah Mada ditemukan berbagai teknik, strategi, profil pemimpin, dan ajaran kepemimpinan yang dilaksanakan oleh Mahapatih Gajah Mada yang kiranya masih relevan untuk dikaji dari perspektif model kepemimpinan Hindu dalam masyarakat Bali, tentunya ada pula hal-hal yang negatif yang tidak patut diteladani (Dharma Putra, Anggara Putu, 2010).

\section{METODE PENELITIAN}

Berdasarkan tema penelitian yang digarap peneliti mengunakan metode sejarah. Menurut Gottschalk (2008), "metode sejarah adalah proses menguji dan menganalisis secara kritis rekaman dan peninggalan masa lampau. Rekontruksi yang imajinatif dari pada masa lalu berdasarkan data yang diperoleh dengan menempih proses itu disebut historiografi (penulis sejarah)".

Menurut Kartodirdjo

"metode sejarah adalaah alat untuk mengorganisasi seluruh tubuh pengetahuan serta mensrtukturasi pikiran. Jadi, metode sejarah berkaitan dengan bagaimana seorang untuk memperoleh penegetahuan mengenai masa lampau".

Dapat diartikan bahwa penelitian historis adalah cara yang digunakan untuk menyelesaikan suatu masalah dengan menganalisis secara kritis peninggalan masa lampau berupa data dan fakta atupun dokumen yang disusun secara sistematis, dari evaluasi yang objektif dari data yang berhubungan dengan kejadian masa lampau untuk memahami kejadian atau kejadian baik masa lampau maupun masa sekarang.

Penulis disini membatasi dalam pembuatan artikel ilmiah ini yang berjudul "Gajah Mada Sang Maha Patih Pemersatu Nusantara di Bawah Majapahit Tahun 1336 M - 1359 M" waktu pembuatan diperkirakan selama 3 bulan.

Tahap-tahap penelitian dengan melandaskan pada teori dan metode serta teknik penelitian yang telah dijelaskan pada pembahasan 
sebelumnya. Pelaksanaan penelitian dilakukan melalui tahapan sesuai dengan metode penelitian yang digunakan yaitu metode historis. Peneliti mengunakan tahapan penelitian sebagimana yang diungkapkan oleh Sjamsuddin (2007), yaitu pengumpulan sumber (heuristik), kritik sumber, serta interprestasi dan penulisan sejarah (historiografi).

Pengumpulan sumber (Heuristik) dilakukan setelah peneliti menentukan topik yang akan dikaji peneliti penyusunan artikel ilmiah. Peneliti memilih topik bahasan berkaitan dengan pemikiran tentang Gajah Mada Sang Maha Patih Pemersatu Nusantara di Bawah Majapahit Tahun $1336 \mathrm{M}-1359 \mathrm{M}$. Setelah penentuan topik, tahapan selanjutnya mencari dan mengumpulkan sumber-sumber sejarah yang relevan dengan masalah atau judul yang akan dikaji. Sumber sejarah menurut Gottschalk (2008) yaitu "tinggalan kehidupan manusia dan hasil aktivitas manusia yang dikomunikasikkan".

Menurut Sjamsudi

"sumber sejarah (historical sources) merupakan segala sesuatu yang langsung atau tidak langsung menceritakan pada kita mengenai suatu kenyataan atau kegiatan manusia pada masa lampau (past actually)". Dari definisi sumber sejarah tersebut, peneliti berusaha mengumpulkan sumber-sumber sejarah, baik sumber primer maupun sumber skunder yang diperlukan dalam penulisan skripsi. Sumber-sumber yang peneliti kumpulkan yaitu sumber berupa bukubuku, jurnal ilmiah, tesis dan skripsi, yang didalamya terdapat tulisan tokoh yang akan peneliti kaji dalam skripsi, yaitu Gajah Mada Sang Maha Patih Pemersatu Nusantara di Bawah Majapahit Tahun $1336 \mathrm{M}-1359 \mathrm{M}$.

Untuk mendapatkan ontentisitas dan kredibilitas sumber, peneliti mencoba melakukan kritik sumber. Menurut Gottschalk (2008) "kritik kerja intelektual dan rasional yang mengikuti metodologi sejarah guna mendapatkan objektivitas suatu kejadian”. Dalam metodologi sejarah kritik sumber meliputi dua tahapan, yaitu kritik eksternal dan kritik internal. Kritik eksternal adalah usaha mendapatkan otentisitas sumber dengan melakukan penelitian fisik terhadap suatu sumber. Kritik eksternal selalu dilakukan sesuai dengan anak zaman, terkait dengan sumber-sumber yang didapat, peneliti melakukan kritik eksternal dengan melihat karya-karya dari aspek pengarang, penerbit dan tahun terbit.

Kritik selanjutnya yaitu kritik internal. Kritik ini mengacu pada kredibilitas sumber, dan bertujuan untuk memahami isi teks. Langkah pertama dalam proses kritik internal yang dilakukan peneliti adalah dengan mengklasifikasikan sumber kedalam dua bagian. Pertama buku-buku karya soeharto yang menjelaskan tentang Gajah Mada, sumber yang kajian utamanya menafsirkan peranan Gajah Mada. Kedua klasifikasi tentang teori tersebut peneliti bandingkan, kemudian mengambil kesimpulannya sebagi sarana dalam mempermudah analisa peneliti terhadap pemikiran tentang Gajah Mada Sang Maha Patih 
Pemersatu Nusantara di Bawah Majapahit Tahun $1336 \mathrm{M}-1359 \mathrm{M}$.

Tahap selanjutnya setelah heuristik dan kritik adalah interpretasi. Dalam tahap interprestasi atau penafsiran peneliti mencoba melakukan tafsiran/interprestasi subjektif dengan selalu mencantumkan sumber yang peneliti gunakan. Menurut Sjamsudi (2007) "dalam tahapan interprestasi peneliti melakukan dua hal, yaitu dengan analisis dan sintesis". Pada tahapan analisis peneliti menguraikan bahasan yang akan dikaji peneliti. Peneliti mencoba menguraikan Gajah Mada Sang Maha Patih Pemersatu Nusantara di Bawah Majapahit Tahun 1336 M 1359 M. Kemudian tahap sintesis, yaitu kebalikan dari analisis, dari uraian-uaraian informasi peneliti mencoba menyatukan dan mengambil kesimpulan tentang Gajah Mada Sang Maha Patih Pemersatu Nusantara di Bawah Majapahit Tahun 1336 M 1359 M.

Setelah melakukan proses analisis terhadap fakta-fakta yang ada, peneliti kemudian menyajikan dalam bentuk tulisan yang disebut historiografi. Historiografi merupakan proses penyusunan hasil penelitian ke dalam bentuk tulisan. Peneliti berusaha menyajikan hasil penelitian dengan gaya bahasa yang menarik dan komunikatif. Penulisan ini mengunakan teknik dasar menulis deskripsi, narasi dan analisis. Menurut Gootschalk (2008) "historiografi adalah rekontruksi yang imajinatif dari masa lampau berdasarkan data yang diperoleh dengan menempuh proses".
Langkah ini merupakan langkah terakhir dalam prosedur penelitian. Historiografi atau laporan hasil penelitian merupakan puncak dari suatu prosedur penelitian sejarah. Setelah melakukan langkah heuristik, kritik, interprestasi seluruh hasil penelitian yang telah diperoleh, disusun menjadi suatu karya tulisan ilmiah berupa artikel ilmiah dalam historiografi.

\section{HASIL DAN PEMBAHASAN Kebesaran Majapahit di bawah Kepimpinan Raja Hayam Wuruk}

Raja Hayam Wuruk dinobatkan sebagai raja Majapahit ketika masih berusia 17 tahun. Tepatnya, Hayam Wuruk menjadi raja setelah Tribhuana Wijayatunggadewi turun tahta untuk kembali menjabat sebagai Bhre Kahuripan yang tergabung ke dalam Saptaprabhu pada tahun 1351 M. Pada tahun tersebut, Gayatri berpulang ke alam kelanggengan. Semasa pemerintahan Hayam Wuruk, Majapahit mengalami puncak kejayaan berkat peran Patih Amangkubhumi Gajah Mada. Puncak kejayaan Majapahit yang ditandai dengan terwujudnya gagasan penyatuan wilayah-wilayah Nusantara. Suatu gagasan yang pernah direalisasikan oleh Kertanegara dan Tribhuwana Wijayatunggadewi (Achmad, Sri Wintala, 2016).

Zaman keemasan Majapahit melekat erat dengan masa pemerintahan Hayam Wuruk, raja keempat Majapahit. Bersama orang yang mengasuhnya sejak kecil, Gajah Mada, Hayam Wuruk membangun Majapahit ke puncak kejayaan berdasarkan falsafah kenegaraan 
Bhinneka Tunggal Ika tan hana dharma mangrwa. Hayam Wuruk lahir tahun 1334, beberapa bulan sebelum Gajah Mada dikukuhkan sebagai Mahapatih Amangkubumi. Pada saat Gajah Mada mengucapkan sumpah sakral Amukti Palapa bayi Hayam Wuruk baru saja menikmati udara Majapahit. Di tangannyalah kemudian seluruh perairan nusantara bersatu menentang penjajahan bangsa asing, terutama Tiongkok (Masmada, Renny, 2003).

Kebesaran Majapahit sebagai negara pemersatu bangsa, nusantara raya, dikenal hampir di seluruh mancanegara pada zamannya dari tahun 1293 sampai 1478. Kemajuan di bidang ekonomi, sosial, budaya dan politik menarik perhatian beberapa negara sahabat, pada zamannya maupun abad-abad belakangan ini. Kebesaran Majapahit, berarti kebesaran Gajah Mada, Patih yang telah mengabdi kepada tiga pimpinan pemerintahan selama lebih dari tiga puluh tahun.

Pada tahun 1343, Majapahit menyerang Bali. Pasukan Majapahit dipimpin oleh bangsawan bernama Usana-Jawa, mengalahkan pasukan Dalem Bedahulu, Raja Pejeng. UsanaJawa ditemani enam komandan, salah satunya Arya Damar. Majapahit menang, dan keluarga bangsawan Bali ditawan. Arya Damar disebut juga Adityawarman. Nama Adityawarman pertama kali disebut dalam patung yang berasal dari tahun 1343 terletak di Candi Jago, Jawa Timur, sebagai perwujudan Bodhisatwa Manjusri. Menurut Pararaton, Adityawarman adalah anak laki-laki dari seorang putri Melayu bernama Dara Jingga yang menikah dengan pangeran Jawa bernama Adwayarman.

Tentara inti Jawa dalam upaya menaklukan wilayah lain disesuaikan dengan medan yang dihadapi. Setiap pengiriman pasukan, baik dalam jumlah besar maupun jumlah kecil, selalu diperhitungkan dengan matang. Dalam banyak peperangan, tentara Jawa memperoleh kemenangan karena dibantu oleh negara lain. Ketika Majapahit mengalahkan Singapura, bantuan Radjuna Tapa begitu besar. Begitu pula ketika mengalahkan Negara Dipa, pangeran dan rakyat Negara Dipa memberikan bantuan kepada tentara Jawa. Karena itu, pengiriman pasukan tidak selalu dalam kekuatan maksimal. Dalam membantu menaklukan Negara Dipa, tentara Jawa yang dikirim tidak lebih dari 1.000 orang (Nugroho, Irawan Djoko, 2010).

Pelaksanaan politik luar negeri dalam rangka penyatuan Nusantara mencapai kemantapannya pada masa pemerintahan Hayam Wuruk. Daerahdaerah yang belum bernaung di bawah kekuasaan Majapahit berhasil disatukan. Pemberitaan Prapanca dalam kitab Negarakertagama menyebutkan bahwa wilayah kekuasaan Majapahit sangat luas. Daerah tersebut meliputi hampir seluas wilayah Republik Indonesia sekarang, yakni Sumatera di bagian Barat, sampai Maluku dan Irian di bagian Timur. Hayam Wuruk sering melakukan perjalanan ke daerahdaerah dalam rangka konsilidasi. Wilayah yang luas, pembinaan perhadap setiap wilayah harus 
dilakukan agar tetap memiliki kesetiaan terhadap pemerintahan pusat di Majapahit. Adanya kunjungan tersebut, wilayah-wilayah di setiap daerah akan merasa diperhatikan oleh Raja Hayam Wuruk (Pinuluh, Esa Damar, 2010).

Berkat jasa Patih Gajah Mada, Raja Rajasanagara berhasil membawa Kerajaan Majapahit ke puncak kebesarannya. Gagasan politik luar negeri mengenai perluasan cakrawala mandala, dilakukannya dengan baik. Gagasan penyatuan Nusantara oleh Gajah Mada satu demi satu ditundukkan. Dari pemberitaan Negarakretagama pupuh XIII - XV diketahui bahwa pengaruh kekuasaan Majapahit sangat luas. Daerah-daerah itu hampir seluas wilayah Indonesia sekarang (Suwardono, 2013).

Masyarakat Majapahit umumnya merupakan masyarakat yang majemuk. Wilayah Kerajaan Majapahit yang sangat luas, dengan segala karakteristik wilayahnya, menjadikan Majapahit memiliki keragaman yang ditentukan oleh banyak hal, wilayah di pedalaman yang bersendikan agraris, akan memiliki pola kebudayaan yang berbeda dengan daerah pantai yang bersendikan perdagangan. Masyarakat pedalaman lebih bersifat tertutup dengan kebudayaan siklus (berputar tetap). Sementara masyarakat pantai yang secara geografis sering berhubungan dengan bangsa asing, lebih bersifat terbuka terhadap hal-hal baru. Kehidupan keagamaan Majapahit menunjukkan pula hubungan dengan sendi-sendi toleransi yang kuat. Majapahit mengakui dan menghormati dua agama besar saat itu, yakni Hindu dan Buddha, dalam bentuk pengangkatan pejabat keagamaan dalam struktur pemerintahannya (Pinuluh, Esa Damar, 2010).

Semasa menjabat menjadi raja, Hayam Wuruk tidak hanya menerapkan kebijakan untuk meningkatkan bidang pertahanan dan keamanan di dalam negeri. Meningkatkan bidang pertahanan dan keamanan, Majapahit di masa pemerintahan Hayam Wuruk terbebas dari ancaman baik dalam maupun luar negeri. Tidak ada pemberontakan yang digenncarkan dari dalam negeri, maupun dari luar negeri Majapahit. Hubungan kerja sama di bidang ekonomi dengan negara-negara tetangga sangatlah penting bagi Majapahit. Hal ini karena Majapahit merupakan sumber barang dagangan yang sangat laku di pasaran. Barang dagangan seperti beras, lada, gading, timah, besi, intan, ikan, cengkih, pala, kapas, dan kayu cendana. Bidang perdagangan, Majapahit memiliki peranan ganda yang sangat penting, yakni sebagai produsen dan perantara (Achmad, Sri Wintala, 2016).

Gajah Mada Sang Maha Patih Pemersatu Nusantara di Bawah Majapahit Tahun 1336 M - 1359 M

Menurut Masmada (2003), setelah Sadeng ditundukkan pada tahun 1331, dan Adityawarman berangkat ke Tiongkok pada tahun 1332 untuk melakukan misi diplomatik kepada Kaisar Tiongkok, Gajah Mada mulai melakukan persiapan dalam negeri. Sebagai seorang ksatria sejati yang sangat peduli terhadap negaranya, hati Gajah 
Mada terketuk melihat keadaan Arya Tadah yang semakin parah. Sementara pemerintahan sedang tumbuh, dan tentunya tidak boleh berhenti hanya karena Arya Tadah tidak mampu lagi menjalankan kebijakannya karena sakit.

Pada saat pengangkatannya itulah Gajah Mada mengucapkan sumpah yang sangat populer: Amukti Palapa! Yang bunyinya sebagai berikut:

Lamun huwus kalah nusantara isun amukti palapa, lamun kalah Gurun, ring Seram, Tanjung Pura, ring Haru, ring Pahang, Dompo, ring Bali, Sunda, Palembang, Tumasik, samana isun amukti palapa. Artinya setelah tunduk Nussantara, aku akan beristirahat. Setelah tunduk Gurun, Seram, Tanjung Pura, Haru, Pahang, Dompo, Bali, Sunda, Palembang, Tumasik, barulah aku beristirahat.

$\begin{array}{rrr}\text { Realisasi dari } & \text { Sumpah Palapa } \\ \text { Gajah } & \text { Mada } & \text { mencapai }\end{array}$ keberhasilannya semasa pemerintahan Hayam Wuruk. Hal ini dapat dibuktikan bahwa Majapahit pada waktu itu mampu menguasai wilayahwilayah Nusantara yang meliputi Melayu (Sumatra), Tanjungpura (Kalimantan), Semenanjung Melayu (Malaka), sebelah Timur Jawa dan Nusa Tenggara, Sulawesi, Maluku, Irian Barat, dan Jawa (kecuali Kerajaan Sunda Galuh dan Sunda Pakuan). Berkat keberhasilannya ini, pengaruh Gajah Mada di Majapahit lebih besar. Bahkan pengaruhnya bisa dikatakan melampau Hayam Wuruk dan anggota Saptaprabhu (semacam
Dewan Pertimbangan Agung yang beranggotakan keluarga Kerajaan Majapahit) (Achmad, Sri Wintala, 2016).

Sampai abad ke-15, Kerajaan Jawa memiliki pasukan yang sangat disegani dan ditakuti di dunia. Hang Tuah yang luar biasa, hanya takut kepada tentara Jawa (Majapahit), bukan kepada Patih Gajah Mada atau Raja Majapahit. Rasa segan karena takut juga ditunjukkan oleh Raja Dinasti Ming. Pada tahun 1377, utusan Raja Dinasti Ming menuju Raja Sumatra Timur dicegat dan dibunuh tentara Majapahit. Tindakan ini tidak mendapat balasan. Padahal, perbuatan ini melebihi perbuatan Raja Kertanegara yang melukai wajah Meng Chi, utusan Raja Mongol, dan Raja Mongol melakukan pembalasan. Ketakutan beberapa negara kepada tentara Jawa bukan tanpa dasar. Selain reputasi tentara Jawa yang mampu menghancurkan tentara Mongol beserta rajanya sebagai tentara terkuat dunia, tentara Jawa merupakan reguler profesional yang berbeda dengan pasukan-pasukan lain pada masanya (Nugroho, Irawan Djoko, 2011).

Hubungan antara pusat Kerajaan Majapahit dengan daerah yang meliputi aspek ekonomi dan bisnis. Secara ekonomis wilayah pengaruh Majapahit dipersatukan dalam rangka kepentingan-kepentingan perdagangan, bukan dalam arti pertuanan atau kekuasaan. Daerah-daerah kekuasaan Majapahit memberikan dukungan ekonomi kepada istana yang ditukar dengan penjagaan keamanan di jalurjalur perdagangan. Pemerintah pusat memandang perlu memberikan 
perlindungan kepada daerahdaerahnya dengan menempatkan pasukan khusus untuk menjaga segala tindak kejahatan yang terjadi pada wilyahnya. Hal ini untuk memonitor segala aktivitas daerah seiring dengan meningkatnya aktivitas perdagangan yang melibatkan daerah-daerah di Nusantara dengan sejumlah pelabuhan di Asia Tenggara, India, dan Pantai Laut Tengah (Pinuluh, Esa Damar, 2010).

$\begin{array}{llr}\text { Puncak } & \text { kejayaan } & \text { Kerajaan } \\ \text { Majapahit } & \text { ditandai } & \text { dengan } \\ \text { terwujudnya } & \text { gagasan } & \text { penyatuan }\end{array}$
wilayah-wilayah Nusantara. Suatu gagasan yang pernah direalisasikan oleh Kertanegara (Raja Singasari terakhir) dan Tribuana Wijayatunggadewi (raja ke tiga Majapahit). Adanya topangan spirit Sumpah Palapa serta politik Patih Amangkubhumi Gajah Mada, Kerajaan Majapahit semasa pemerintahan Hayam Wuruk tersebut berhasil mengembangkan wilayah kekuasaannya di seluruh Nusantara. Sempat terjadi perang Bubat karena saat bersitegang antara Kerajaan Majapahit dengan Kerajaan Sunda Pajajaran yang menewaskan Prabu Linggaubuana, Dyah Pitaloka beserta pembesar istana Sunda Pajajaran.

Pada tahun 1389, setelah mengantarkan Majapahit ke percaturan sejarah dunia, serta menjalankan roda pemerintahan Majapahit dengan gemilang, Hayam Wuruk dikabarkan meninggal di usia 55 tahun. Tampuk kekuasaan Majapahit kemudian diturunkan oleh Kusumawardani. Akan tetapi, Wikramawardhanalah yang tercatat menggantikan kursi pemerintahan Majapahit selanjutnya. Sepeninggalan Hayam Wuruk, kejayaan Majapahit berangsur-angsur surut. Kesurutan yang menyebabkan terlepasnya beberapa wilayah bawahan Majapahit itu dikarenakan perselisihan antara Wikramawardhana dan Bhre Wirabhumi yang merupakan saudara tiri Kusumawardhani. Perselisihan yang mengakibatkan perang saudara (Perang Paregreg) pada tahun $1401 \mathrm{M}$ (Adji, Krisna Bayu, dkk, 2013).

\section{SIMPULAN}

Masa pemerintahan Hayam Wuruk menjadi masa-masa keemasaan Majapahit dibawah pemerintahan Gajah Mada. Posisi Gajah Mada sebagai Mahapatih, jabatan tertinggi setelah Raja. Adanya Sumpah Palapa yang diucapkan Mahapatih Gajah Mada mengangkat sumpah Amukti Palapa yang berbunyi: "Lamun huwus kalah Nusantara isun amukti palapa, lamun kalah ring Gurun, ring Seran, Tanjung Pura, ring Haru, ring Pahang, Dompo, ring Bali, Sunda, Palembang, Tumasik, samana isun amukti palapa." Seturut sumpah itu, Gajah Mada mengatakan ada 10 wilayah di Nusantara yang harus mengakui kejayaan Majapahit, yaitu Gurun (Lombok), Seran (kepala burung di Papua), Tanjung Pura (Kalimantan), Haru (Sumatera Utara), Pahang (Semenanjung Melayu), Dompo (Sumbawa, dekat Bima), Sunda (Jawa Barat), Bali, Palembang (Sumatera Selatan), dan Tumasik (Singapura).

Raja Hayam Wuruk dan juga Mahapatih Gajah Mada telah 
membawa kejayaan bagi Kerajaan Majapahit di masa itu, dimana wilayah kekuasaan yang sangat luas dan armada perang yang tangguh. Rakyat hidup dalam kemakmuran dan rasa toleransi sangat terjaga dikepemimpinan tokoh sejarah tersebut. Sejarah Melayu menyebut Gajah Mada berhasil menaklukkan Tumasik yang telah menjadi jalur strategis dari Selat Malaka ke Laut Cina Selatan dan sebaliknya. Gajah Mada juga diberitakan telah menyerang Sriwijaya dan lalu Pasai pada 1350. Penduduk setempat di Pasai menyatakan ada bukit di dekat Kota Langsa bernama Manjak Pahit, yang berasal dari kata Majapahit.

Setelah terjadi perang bubat antara Kerajaan Majapahit melawan Kerajaan Sunda Pajajaran yang menewaskan Raja, Permaisuri, Petinggi Kerajaan dan Putri Dyah Pitaloka serta pasukan Kerajaan Pajajaran, nama Gajah Mada semakin redup. Hal ini karena penyerangan tentara Majapahit terhadap Kerajaan Pajajaran di Bubat sangat disayangkan Raja Hayam Wuruk. Sampai pada akhirnya Mahapatih Gajah Mada Moksa dan Raja Hayam Wuruk meninggal, sehingga kepemimpinan Kerajaan Majapahit diberikan kepada keturunan selanjutnya.
DAFTAR PUSTAKA

Achmad, S., W, (2016). 13 Raja

Paling

Berpengaruh

Sepanjang Sejarah Kerajaan di Tanah Jawa. Yogyakarta: Araska.

Dalam Sejarah Politik

Majapahit. Yogyakarta:

Araska.

Bayu, A., K, (2013). Majapahit

Menguak Majapahit

Berdasarkan Fakta Sejarah.

Yogyakarta: Araska.

Dharma P., A., P, (2010). Ajaran Kepemimpinan Dalam Kakawin Gajah Mada Perspektif Model Kepemimpinan Hindu Dalam Masyarakat Bali.

Djafar, H. (2009). Masa Akhir Majapahit: Girindrawardhana dan Masalahnya. Jakarta: Komunitas Bambu.

Gottschalk, L, (2008). Mengerti Sejarah. Jakarta: Buku Beta

Kartodirjo, S, (2005). Pengantar Sejarah Indonesia Baru : Sejarah Pergerakan nasional. Bentang Pustaka.

Masmada, R, (2003). Gajah Mada sang Pemersatu Bangsa. Jakarta: Elex Media Komputindo.

Nugroho, I., D, (2011). Majapahit Peradaban Maritim Ketika Nusantara Menjadi Pengendali Pelabuhan Dunia. Jakarta: Suluh Nuswantara Bakti.

Pinuluh, E., D, (2010). Pesona Majapahit. Yogyakarta: Buku Biru.

Sjamsuddin, H. (2007). Metodologi Sejarah. Jakarta: Ombak.

Suwardono, (2013). Sejarah Indonesia Masa Hindu-Budha. Yogyakarta: Ombak 